Article

\title{
Psychological Barriers to Pro-Environmental Behaviour Change: A Review of Meat Consumption Behaviours
}

\author{
Catherine Graves ${ }^{1, *(D)}$ and Katy Roelich ${ }^{1,2}$ \\ 1 Sustainability Research Institute, University of Leeds, Leeds LS2 9JT, UK; k.e.roelich@leeds.ac.uk \\ 2 School of Civil Engineering, University of Leeds, Leeds LS2 9JT, UK \\ * Correspondence: ee14cg@leeds.ac.uk
}

check for

updates

Citation: Graves, C.; Roelich, K.

Psychological Barriers to

Pro-Environmental Behaviour

Change: A Review of Meat

Consumption Behaviours.

Sustainability 2021, 13, 11582.

https://doi.org/10.3390/

su132111582

Academic Editors:

Dorothea Schaffner and

Haywantee Ramkissoon

Received: 20 August 2021

Accepted: 15 October 2021

Published: 20 October 2021

Publisher's Note: MDPI stays neutral with regard to jurisdictional claims in published maps and institutional affiliations.

Copyright: (C) 2021 by the authors. Licensee MDPI, Basel, Switzerland. This article is an open access article distributed under the terms and conditions of the Creative Commons Attribution (CC BY) license (https:/ / creativecommons.org/licenses/by/ $4.0 /)$.

\begin{abstract}
Meat consumption behaviours contribute significantly to global greenhouse gas emissions. Interventions to enable meat consumption reductions need to consider the psychological barriers preventing behavioural changes. Our aims were twofold; (1) to explore the psychological barriers to reducing meat consumption and how they can be overcome through a Rapid Evidence Review; and (2) to explore the usefulness of integrating the Kollmuss and Agyeman (K\&A) model of proenvironmental behaviour and psychological distance, which provides the analytical framework. This review utilised three databases, focussing on empirical studies since 2010, which returned 277 results with seven eligible studies. We found that habit is the most significant psychological barrier to change, however, values and attitudes could act as moderating variables. We found gaps in the behavioural mechanism, indicating the presence of direct and indirect psychological barriers. We identified several actionable policy recommendations, such as utilising co-benefits, the importance of values in messaging, and targeting repeated behaviours. We found that study outcomes did not always translate into policy recommendations, and they were limited by existing policy paradigms. Psychological distance provides additional explanatory power, when combined with the K\&A model, therefore, integrating psychological distance across pro-environmental behavioural research and policy could improve the effectiveness of interventions.
\end{abstract}

Keywords: pro-environmental behaviour; meat consumption; psychological distance; psychological barriers; climate change

\section{Introduction}

The climate impact of food and agriculture more broadly is estimated to account for 19-29\% of global greenhouse gas (GHG) emissions [1], with livestock alone accounting for $18 \%$ of total GHG emissions [2]. Emissions associated with food supply is a universal issue, however, responsibility for unsustainable meat consumption lies predominantly with the most developed nations. Meat consumption in the UK has been estimated at $81.5 \mathrm{~kg}$ /year/person, which is well above the global average of $43 \mathrm{~kg} /$ year/person [3], and exceeding the recommended nutritional intake [1]. Overconsumption of meat contributes to a range of sustainability issues beyond and related to climate change, such as land-use change, deforestation, desertification, biodiversity loss, water scarcity, nutrient cycles, and equity and justice issues such as geographically and temporally variable food and water insecurity. Reducing meat consumption through shifting to a plant-based diet, finding meat alternatives or simply reducing meat consumed can have a significant impact on an individuals' and national emissions profile.

Existing research has been conducted around motivators, drivers, attitudes, intervention studies, and environmental and contextual barriers (such as cost, availability, culture $[4,5]$ in relation to meat consumption behaviours. Factors such as the environmental and climate impacts of meat [6,7]), motivations and attitudes around reducing meat consumption [8,9], the role of external factors [10], and the effects of different interventions $[11,12]$ have been considered. Existing work has focused on how to encourage meat 
consumption reductions [12-14]; however, more research on the psychological barriers blocking or hindering meat consumption reduction is needed to ensure interventions are as effective as possible [15]. To our knowledge, no systematic or rapid evidence review has solely focussed on psychological barriers to behaviour change.

Psychological barriers are factors within a behavioural mechanism that prevent a different or new behaviour from occurring [16]. An example of this could be blocking new knowledge due to existing emotional attachment. The importance of psychological barriers to reducing meat consumption should not be ignored. Barriers could explain the gap between attitude and intention [9,16], or intention and behaviour [17], or other gaps which prevent a pro-environmental behaviour occurring, which cannot be explained by an absence of behavioural determinants. There is need for more research around psychological barriers to changing high-impact behaviours [18,19], including meat consumption, which is an important high-impact behaviour in terms of per capita emissions [20].

Research on "spillover" behaviours suggests overcoming barriers to one pro-environmental behaviour, such as reducing meat consumption, can have co-benefits across other behavioural domains [21,22]. Solely considering behavioural determinants and drivers within research and policy risks missing significant emissions mitigation potential, through ineffective policy resulting in suboptimal behavioural shifts or potential rebound effects [23]. Overcoming psychological barriers to meat consumption reduction could provide a longterm strategy to achieving a variety of policy aims, extending beyond climate and environmental policy.

Despite widespread political and public understanding of the need to alter individual and household behaviours to mitigate climate change, behavioural change policy is muted and unambitious due to the focus on technocratic policy options [24]. Policy remains focused on encouraging or facilitating behaviour through drivers as opposed to targeting barriers to overcome. Most policies relating to pro-environmental behaviour are focused on knowledge transfer or awareness raising [25], despite the information deficit model being widely understood to be too simplistic [26]. Two types of messaging for awareness-raising are commonly applied in meat consumption interventions: health and moral concerns. However, disgust (emotion) was found to be a somewhat more effective message [27], as health messages are often misunderstood [28].

As psychological barriers to reducing meat consumption are under-researched and under-utilised within policy, compared to behavioural determinants, a Rapid Evidence Review is appropriate to synthesise existing evidence on how psychological barriers prevent meat consumption reduction, in order to contribute to this literature gap. Barriers to behaviour change are increasingly being included in studies on meat consumption reduction, but often alongside drivers [10], and often are conceptualised as the absence of drivers. Therefore, this paper explores barriers as independent behavioural variables in their own right. External barriers-for instance; the cost of meat alternatives, availability of alternatives, etc.- - are excluded to focus on psychological processes and barriers such as the role of emotional attachment, habit and values. This research uses two frameworks as the theoretical foundation and analytical framework in which to explore the psychological barriers to reducing meat consumption: the Kollmuss and Agyeman [29] model and Psychological Distance.

\section{Aims and Research Questions}

A Rapid Evidence Review enables a rigorous yet time-efficient method of evidence synthesis around a focussed issue, structured around three research questions:

RQ1: How can psychological barriers to pro-environmental behaviour change affect meat consumption in individuals?

RQ2: How does psychological distance manifest as a barrier to meat consumption reduction?

RQ3: How can these psychological barriers be overcome? 
Firstly, we detail the theoretical grounding which provides the analytical framework for the review. The Rapid Evidence Review methodology is then outlined before analysing the findings within the framing of the theoretical integration, structured through the three research questions. The discussion primarily focusses on the third research question; how to overcome the psychological barriers to meat consumption reduction. This followed by recommendations for policy and research, and reflections on the usefulness and application of the theoretical framework.

\section{Methods}

\subsection{Theoretical Grounding}

Behavioural theory guides much of the existing research on meat consumption behaviours, as it determines (explicitly or implicitly) how behaviour is researched and what factors are included. Factors such as knowledge, values, and attitudes are nearly always included in studies. Fewer studies also include norms (following the Value-Belief-Norm Theory [30]), perceived behavioural control (following the Theory of Planned Behaviour [31]), habits [32], emotion [27], or awareness [8,9]. Research integrating barriers of any kind is limited (e.g., Gifford, 2011 [18]), and behavioural models mirror the dominance within the pro-environmental behaviour literature by focusing on the determinants of behaviour only. Research across food or health disciplines favours differing theories to sustainability or climate disciplines researching similar issues, such as the Protection Motivation Theory [33] instead of the Theory of Planned Behaviour.

Pro-environmental behaviour change can be viewed as a dynamic process, whereas most models commonly applied do not consider the process after the "action" or behaviour change has occurred [19]. The models are generally linear structures (e.g., Value-BeliefNorm Theory [30] and Theory of Planned Behaviour [31]), which could be due to the lack of longitudinal studies on actual behaviour, i.e., either observed or self-reported.

\subsubsection{Kollmuss and Agyeman (2002) Model of Pro-Environmental Behaviour}

Kollmuss and Agyeman (K\&A) [29] explored the gap between knowledge/awareness and behaviour, and they proposed a model with behavioural determinants and barriers that block the path to behaviour change. This model brought together behavioural factors and models across psychology and sociology (see Figure 1). The novelty in the model is largely based on the explicit use and placement of barriers within the framework of behavioural determinants.

The Kollmuss and Agyeman (K\&A) study became a seminal work within the proenvironmental behaviour change literature; however, it is not without critique due to the sheer breadth of the model. Complexity is the most prominent critique-as a wide array of perspectives have been integrated into a relatively deductive framing [34]. This model was selected as the analytical framework for this research because of its breadth; however, that comes at the cost of contextual complexity. However, what K\&A do not conceptualise is the notion of gaps and distances within the behavioural process that potentially could exclude significant elements of an individual's behaviour change process, rendering subsequent findings and/or policy recommendations ineffective. Therefore, psychological distance is identified as a complementary concept to integrate into the analytical framework in order to address this. 


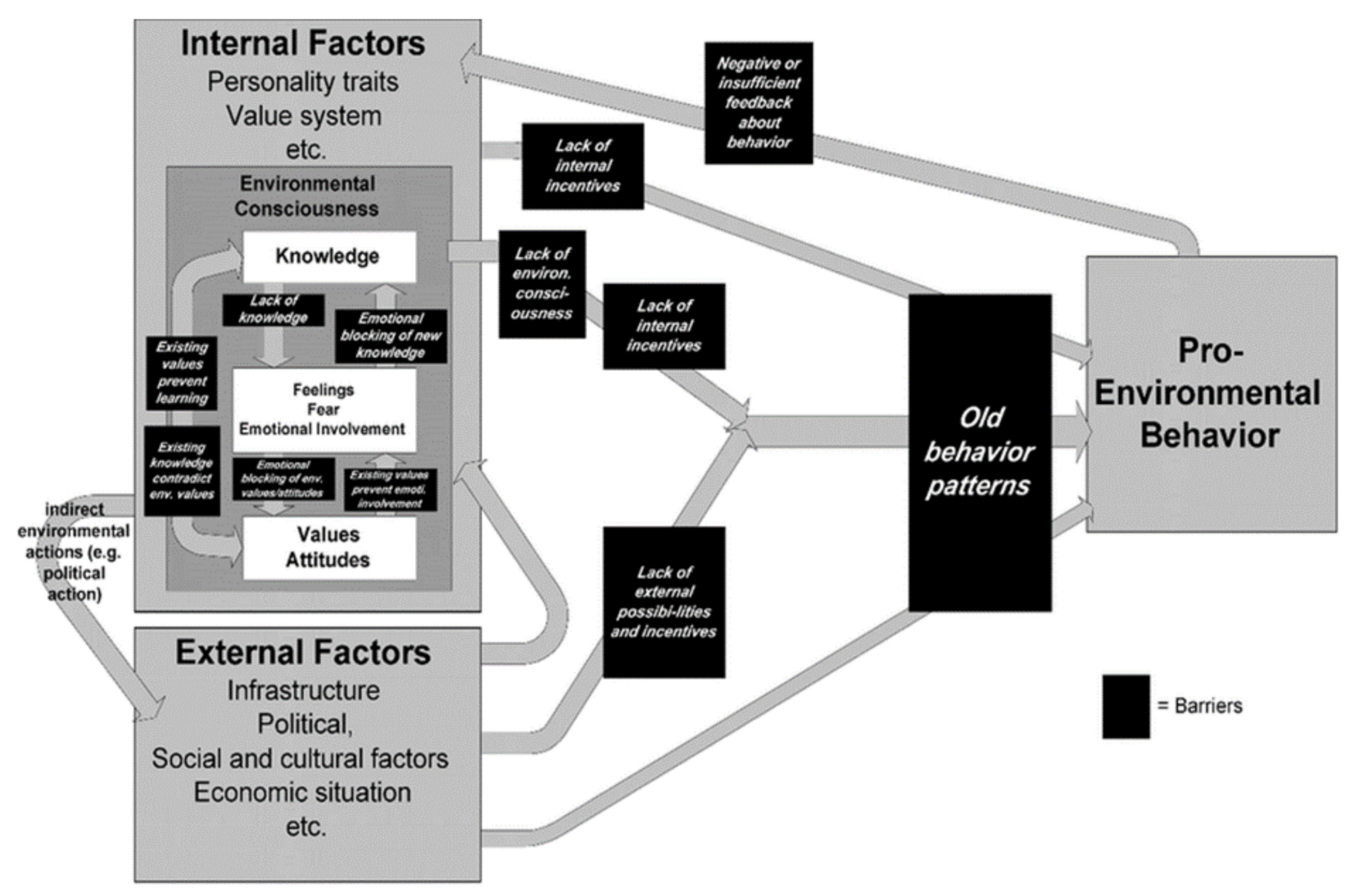

Figure 1. Kollmuss and Agyeman model of pro-environmental behaviour.

\subsubsection{Psychological Distance}

Psychological distance is rooted in risk literature [35] and is defined as "an individual's perception of how removed an object, risk, or event is from that individual" [36] (p. 94). Within the context of climate change, this generally manifests as proximity relating to concern, willingness and action [37], and this can manifest consciously and unconsciously. Trope and Liberman ([38], p. 9) proposed the Construal Level Theory, which outlines four dimensions of psychological distance, namely "time, in space, in social distance, and in hypotheticality", which Spence et al. [39] apply to climate change specifically and interpret as spatial, social, uncertainty, and temporal distances. Loy and Spence [40] identified two strategies for overcoming psychological distance- "proximising" (focusing on local impacts) and "bridging" (increasing the notion of global identity); both are found to reduce the psychological distance perceived.

\subsubsection{Theoretical Integration}

This research combines these two understandings of psychological barriers into an analytical framework. Kollmuss and Agyeman specifically identify how barriers interact with behavioural determinants, whereas most models focus on determinants as proxies for barriers. The notion of the gap between concern and behaviour identified in Kollmuss and Agyeman can be considered conceptually similar to psychological distance- - the idea that gaps (or distances) between and within elements of our understandings prevents behaviour change. These two concepts could combine to increase explanatory power for practical and theoretical benefits, and assist in creating more effective interventions [41].

\subsection{Rapid Evidence Review}

The Rapid Evidence Review (RER) protocol was developed in February 2020, in response to a policy need, and a time-stamped copy is registered in Open Science Framework (doi:10.17605/OSF.IO/URW64). The RER was conducted between February and May 2020, 
and it differs from a full systematic review, as it (1) only involved 1 reviewer, (2) was limited searches to 3 databases, and (3) the searches were not repeated several months later, as is common with systematic reviews. Due to the rapid nature of this review, results were limited to work published post-2010 in order to ensure relevance of findings and enable efficiency of the review to be balanced with comprehensiveness.

\subsubsection{Scoping Search}

The research questions were developed through concept mapping and a scoping search of the existing literature around meat consumption behaviour. A scoping search identified five key papers [1,10-12,42], which were used to develop a concept map that informed the PICOS framework (population, intervention, comparison, outcome, and study context), and subsequent search strings.

\subsubsection{Search Strategy}

The exclusion and inclusion criteria were developed in line with the research questions, using the standard PICOS format (See Supplementary Materials. The search strategy was developed iteratively from the inclusion/exclusion criteria, and trialled across different databases. A review by Taufik et al. (2019) [12] helpfully included very detailed search strings, and this ensured the current study was as specific as possible, especially in regards to synonyms of behaviour and exclusions of study participants.

The searches were run and downloaded into Zotero (See Supplementary Materials). Web of Science, Scopus and Google Scholar were used. Google Scholar returned 1640 results and the first 200 were included, to balance comprehensiveness with speed. Citation searching of the 5 key papers was then conducted as a check of saturation, and 1 paper was added. This ensures confidence in the comprehensiveness and effectiveness of the search strings. The full searches returned 277 results. The first sift applied the inclusion and exclusion criteria to the title and abstract, with a full paper analysis for the second sift. The two rounds of sifting resulted in 7 papers being included in this study (PRISMA diagram; Supplementary Materials).

\subsubsection{Data Extraction}

The data extraction framework was based on the research questions (Supplementary Materials), and the use of the critical appraisal framework distinguishes a systematic or Rapid Evidence Review from standard literature reviews. This was adapted from Rees et al. [43], as it combines the key elements of critical appraisal and risk of bias, whilst being relatively low intensity (Supplementary Materials: Critical Appraisal). The papers were scored $0-3$ for each criteria, with a maximum 18 points, and this corresponded to a low (0-6), medium (7-12), or high (13-18) score.

\subsubsection{Data Synthesis}

Once the data was extracted, a narrative, thematic approach drove the synthesis. This followed two tracks: study outcomes and policy recommendations. Study outcome data was themed deductively, in accordance with categories within Kollmuss and Agyeman (K\&A) [29] and Spence et al.'s [39] application of psychological distance. The K\&A model provide detailed barriers, such as "existing values prevent learning"; however, for simplicity and to enable comparison, barriers were grouped into themes of values, emotion, knowledge, and habit. Study outcomes cannot be directly compared, however, findings can be synthesised to extract trends and potentially contradictory and complementary results. The study outcomes refer to the findings and conclusions for each study that relate to psychological barriers. Policy recommendations were inductively themed, by iteratively identifying common threads and findings. The study outcomes and policy recommendations were differentiated in order to critically assess whether the recommendations for policy align with the barriers identified, and what any discrepancy might reflect. 


\section{Results}

\subsection{Study Design Synthesis}

Seven articles were included in this Rapid Evidence Review: four quantitative, two qualitative, and one mixed-methods research design (Table 1). The studies all measured similar dependent variables: (self-reported) behaviour, intention, and awareness/attitudes around reducing meat consumption. None of the studies looked exclusively at psychological barriers, and psychological barriers were often included alongside external barriers (e.g., availability, price of meat-alternatives, etc.). Three studies explored psychological barriers directly (i.e., use specific metrics), two used other determinants as proxies for barriers (e.g., absence of motivation, agency, self-efficacy, etc.), and the two qualitative studies drew out narrative themes in relation to psychological barriers. All studies were conducted in Europe, Australia, or the US, so sociodemographic and cultural limitations need to be recognised. The discourse varies, as studies are split across "reducing meat consumption" (three studies), "adopting a plant-based diet" (two), "alternatives to meat" (one), and "climate-friendly food choices" (one).

Table 1. Summary table of included studies, including reference code, study design, headline findings, and critical appraisal.

\begin{tabular}{|c|c|c|c|c|c|}
\hline Reference & Code & Research Question & Study Design & Study Outcomes & $\begin{array}{c}\text { Role of Psychological } \\
\text { Barriers }\end{array}$ \\
\hline $\begin{array}{l}\text { Circus and Robison } \\
\text { (2019) [49] }\end{array}$ & Cir19 & $\begin{array}{c}\text { Consumer } \\
\text { perceptions of } \\
\text { sustainable protein }\end{array}$ & $\begin{array}{l}\text { Mixed (interviews } \\
\text { and survey) }\end{array}$ & $\begin{array}{l}\text { Plant-based } \\
\text { substitutes preferred }\end{array}$ & $\begin{array}{l}\text { Moral and ethical reasons } \\
\text { are barriers and drivers }\end{array}$ \\
\hline $\begin{array}{l}\text { Hoek et al., (2017) } \\
\text { [44] }\end{array}$ & Hoe17 & $\begin{array}{l}\text { Attitudes, experience, } \\
\text { perception of } \\
\text { sustainable food } \\
\text { choices }\end{array}$ & $\begin{array}{l}\text { Qualitative (in-depth } \\
\text { interviews) }\end{array}$ & $\begin{array}{c}\text { Motivation } \\
\text { discrepancy: "reduce } \\
\text { meat consumption" } \\
\text { and "increase plant } \\
\text { based diet" }\end{array}$ & $\begin{array}{l}\text { Habit biggest barrier, } \\
\text { health second most } \\
\text { prevalent. Low } \\
\text { awareness of } \\
\text { environmental impact of } \\
\text { meat. }\end{array}$ \\
\hline $\begin{array}{l}\text { Hunter and Roos } \\
\text { (2016) [45] }\end{array}$ & Hun16 & $\begin{array}{l}\text { Meat consumption } \\
\text { reduction } \\
\text { motivations }\end{array}$ & Quantitative (survey) & $\begin{array}{l}\text { Higher self-efficacy } \\
\text { increases adoption of } \\
\text { alternatives }\end{array}$ & $\begin{array}{l}\text { Perceived difficulty of } \\
\text { new behaviour and } \\
\text { knowledge of climate } \\
\text { impact most significant. } \\
\text { Threat other vs. threat } \\
\text { close. }\end{array}$ \\
\hline Kemper (2020) [5] & Kem20 & $\begin{array}{l}\text { Lifecycle stage } \\
\text { variation in reduction } \\
\text { of meat consumption }\end{array}$ & $\begin{array}{l}\text { Qualitative (focus } \\
\text { groups) }\end{array}$ & $\begin{array}{l}\text { Barriers act across } \\
\text { demographics. } \\
\text { Culture and values } \\
\text { affect reductions }\end{array}$ & $\begin{array}{l}\text { Health can be barrier or } \\
\text { motivator. Knowledge: } \\
\text { low effect. Enjoyment } \\
\text { and values barriers }\end{array}$ \\
\hline $\begin{array}{l}\text { Makiniemi and } \\
\text { Vainio (2014) [46] }\end{array}$ & Mak14 & $\begin{array}{l}\text { Comparison of } \\
\text { self-perceived } \\
\text { barriers and } \\
\text { self-reported } \\
\text { behaviour }\end{array}$ & Quantitative (survey) & $\begin{array}{l}\text { Dissociation of } \\
\text { self-perception of } \\
\text { barriers and } \\
\text { behaviours }\end{array}$ & $\begin{array}{l}\text { Lack of knowledge } \\
\text { perceived as biggest } \\
\text { barrier. Habit and } \\
\text { disbelief in climate } \\
\text { impact most significant }\end{array}$ \\
\hline $\begin{array}{l}\text { Pohjolainen et al. } \\
\text { (2015) [47] }\end{array}$ & Poh15 & $\begin{array}{l}\text { Prevalence of barriers } \\
\text { to plant-based diet }\end{array}$ & Quantitative (survey) & $\begin{array}{l}\text { Barriers work } \\
\text { together to form one } \\
\text { "barrier dimension" }\end{array}$ & $\begin{array}{c}\text { Enjoyment is biggest } \\
\text { barrier, then familiarity, } \\
\text { and perception of health } \\
\text { benefits. Difficulty } \\
\text { important }\end{array}$ \\
\hline $\begin{array}{l}\text { Urbanovich and } \\
\text { Bevan (2020) [48] }\end{array}$ & Urb20 & $\begin{array}{c}\text { Most common } \\
\text { self-reported barriers } \\
\text { and benefits of } \\
\text { plant-based diet }\end{array}$ & Quantitative (survey) & $\begin{array}{c}\text { Norms, habits, } \\
\text { self-efficacy are } \\
\text { moderating variables }\end{array}$ & $\begin{array}{l}\text { Habits biggest barrier. } \\
\text { Norms biggest predictor } \\
\text { of behaviour }\end{array}$ \\
\hline
\end{tabular}

Five studies performed well in the critical appraisal (CA) in terms of rigour and clarity of evidence presented (Hoe17 [44], Hun16 [45], Mak14 [46], Poh15 [47], and Urb20 [48]). Two studies scored poorly (Cir19 [49] and Kem20 [5]); however, as this was assessed to be due to the lack of evidence presented as opposed to poor research design, all papers were weighted equally. There is a general issue of external validity, as is common across behavioural studies. 


\subsection{Research Question 1: How Can Psychological Barriers to Pro-Environmental Behaviour} Change Affect Meat Consumption in Individuals?

Using the K\&A model as the framework with which to analyse the outcomes from each study, we grouped specific barriers thematically (by values, emotions, knowledge, and habit). Habits were found to be the most significant and frequently identified barrier, and values and attitudes were often identified as co-variates to other barriers.

\subsubsection{Habit}

Habits were identified as the most significant barrier in three of the studies (Hoe17, Mak14, Urb20), with a fourth (Poh15) identifying habit as the strongest predictor of a "barrier effect", and a fifth (Kem20) relating habit and difficulty. Despite the small sample size of studies, this provides interesting insight. Habits are often referred to explicitly (or discussed as "existing behaviour" or "behavioural patterns"). This could affect its prominence in the results, as other barriers have a higher degree of subjectivity involved. Habit could be linked to difficulty in changing behaviour (Kem20), familiarity with meat eating behaviour (Poh15), and potentially perceptions of "unnaturalness" (Cir19) (in relation to lab-grown alternatives).

\subsubsection{Values and Attitudes}

Values and attitudes were not identified as a significant barrier to behaviour change, but they were discussed extensively in five studies. Values were much more widely referenced than attitudes. Values relate to emotion, especially through cultural norms (Hoe17 and Urb20) and heritage (Poh15, Kem20). An attitudinal dichotomy was identified (Cir19, Hoe17) between discourses of "reducing meat consumption" (negative) and "increasing plant-based diet" (positive). Moral and ethical reasons were classified as a values-related barriers, although it could be argued that there is a psychological distance-related component within those considerations, i.e., distance between self-animal-food. Perhaps surprisingly, moral and ethical reasons were only discussed in two studies (Cir19 and Urb20) and neither found ethical issues a dominant barrier to behaviour change. Values are linked to emotion and norms, without themselves being the most significant barrier. This suggests that values/attitudes act as covariates or moderating variables, therefore, their relative importance may not be fully recognised within these studies.

\subsubsection{Emotion}

Emotional factors were identified as barriers in four studies, with one (Poh15) categorising enjoyment of meat as the most significant barrier to change. Cir19 explored this concept explicitly in their research and found meat attachment affected preference and willingness to consume alternative diets (e.g., lab-grown meat, meat substitutes, and insects). Attachment to meat is discussed almost interchangeably with enjoyment of meat across all studies, and this complements Hun16's question of what the emotional cost of not eating meat is. Only one emotional positive from reducing meat consumption was discussed; where Hoe17 identified individuals 'feeling better about themselves' when eating a plant-based diet. Emotional barriers are found to be linked to values, such as associations with childhood (Kem20) and notions of cultural norms (Hoe17).

\subsubsection{Knowledge}

Knowledge was discussed as a barrier in five studies, and identified as a significant barrier in Hun16. The common theme was 'understanding of the environmental impact of meat consumption' (Hoe17, Hun16, and Kem20), but knowledge of climate friendly foods (Mak14) and nutritional information (Urb20) also appear. Although it appears as a barrier in five studies, Kem20 finds knowledge has a low effect on motivation to overcome barriers.

The interrelationships and interdependencies with and between the barriers are apparent throughout. No barrier exists in isolation, and this supports the conceptualisation of barriers and the broader behavioural process discussed in Kollmuss and Agyeman 
(2002) and Poh15's discussion of the usefulness of a holistic 'barrier concept'. The four categories within K\&A capture a significant proportion of the study outcomes, however, the remaining study outcomes around psychological barriers are further explored using psychological distance.

\subsection{Research Question 2: How Does Psychological Distance Manifest as a Barrier to Meat Consumption Reduction?}

The remaining study outcomes which did not fit into the K\&A model were coded for references to distances (conceptual or literal), gaps, or other types of disconnection, which fitted within the understanding of psychological distance. The data extracted was categorised within the four elements of psychological distance (social, spatial, temporal, and uncertainty) [39]. This proved more subjective than categorising barriers within the K\&A model, as psychological distance is not a concept explicitly referenced in the included studies.

The two main findings were that 'social' and 'uncertainty'-related distances dominated the study outcomes, and that social distance did not manifest as expected based on current understandings of psychological distance. No outcomes were specifically categorised as 'temporal' psychological distance, and 'spatial' psychological distance only was assigned one outcome (Figure 2). 'Understanding of the severity and vulnerability to climate change' cuts across all types of psychological distance, and is a broad theme that could link to many of the previously identified barriers (e.g., knowledge and threat).

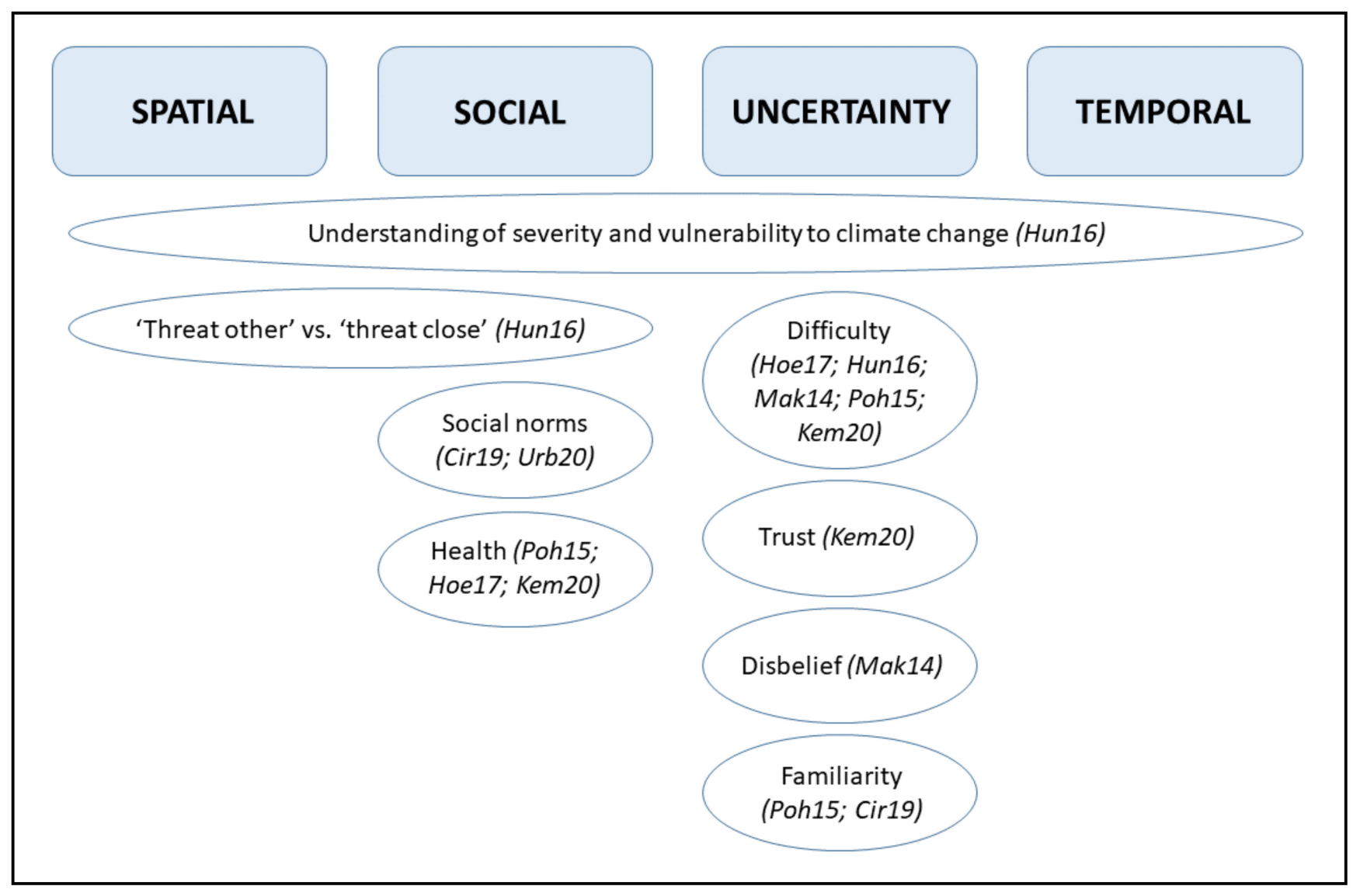

Figure 2. Study outcomes categorised by type of psychological distance.

The findings identify psychological closeness/proximity as the dominant dimension of social distance. Increased social distance was not identified as a barrier to reducing meat consumption, as individuals advocated for behaviour in others that they themselves would apply (Cir19), and Hun16 identified 'threat other' (from climate change) as a smaller 
barrier to change than 'threat close'. This contradicts the common assumption within psychological distance that the further from the 'self' the issue is, the less the self will care or change behaviour. However, study outcomes which conceptualised the issue as close to the self (close psychological distance), for instance through health (Hoe17, Kem20, and Poh15) and the effect of social norms (Urb20), found those to have a positive effect on overcoming barriers to change. These findings raise the issue that norms are not explicitly explored in K\&A, which could indicate a gap, due to the prominence in other models (i.e., Value-Belief-Norm Theory [30] and the General Model of Social Dilemmas [50]). The findings suggest that dimensions of social distance can be categorised as both barriers and solutions to overcoming barriers.

Five study outcomes were categorised as 'uncertainty'. Difficulty was identified in five studies, and has been categorised as uncertainty as it related to a lack of nutritional understanding (Urb20), skills required (Hun16, Kem20), and to a gap between the perceived difficulty of consuming less meat/eating a plant-based diet, and the actual difficulty (Hoe17). 'Disbelief in climate impact' (Mak14 and Urb20) is a theme that could be based on low knowledge of environmental impact (as in K\&A), and/or be a manifestation of psychological distance. Difficulty and disbelief occur alongside knowledge gaps, in relation to nutritional literacy and understanding of the climate impact of meat. Disassociation between the self-perception of barriers and actual barriers that Mak14 identified, could explain this. Mak14 found that disbelief was a significant self-perceived barrier, whereas, lack of knowledge was identified as the third most relevant actual barrier. This indicates that other barriers affect disbelief (i.e., values), or that disbelief is not as significant as it is perceived within the individual.

Psychological distance revolves entirely around the self; i.e., the gap between the self and climate impacts, the self and wider social norms, and the self and perception of self. These findings indicate that distances manifesting as 'uncertainty' present barriers to changing meat consumption behaviour, whereas social distance presented a much more nuanced picture; and could be utilised for behavioural interventions.

\section{Outliers}

Three barriers do not neatly fit into either the K\&A model or psychological distance:

- Self-efficacy;

- Self-perception of barriers and behaviour;

- Gap between perception of 'reducing meat consumption' and 'increasing plant based diet'.

All three manifest as a gap between elements of the behavioural process. Self-efficacy could be conceptualised as a gap between behavioural determinants and agency. The gap between the perception of both barriers and behaviour can occur at any stage of the behavioural process and prevent a new behaviour from occurring. The difference in perception based on the framing of either 'reducing meat consumption' or 'increasing plant-based diet' could relate to a gap between emotion (e.g., meat attachment) and values (e.g., resentment about reducing/limiting behaviour). All three are rooted in the gap between an individual's perception of self or their perception of the issue; and the reality (be that their actual behaviour, or their ability to change behaviour).

\subsection{Research Question 3: How Can These Psychological Barriers Be Overcome?}

In order to explore how the barriers could be overcome, the policy recommendations from the studies were coded inductively, which resulted in four themes:

(1) The importance of messaging and framing;

(2) Co-benefits with other issues (predominantly health);

(3) The use of knowledge and information;

(4) The role of theory.

The most frequently recommended action is for appropriate and tailored messaging and framing; five studies focused on that as a key strategy. This should be tailored to values 
and norms, otherwise, it risks being counterproductive (i.e., high meat attachment individuals resisting a plant-based diet; meat alternatives would be more appropriate (Cir19)). Messaging could be targeted at those more sympathetic to changing behaviour (Poh15), different stages of the 'meat reduction journey' (Kem20), using multiple approaches to change behaviour (Hoe17), and targeting different drivers (Cir19). Using 'co-benefits' such as health (Hoe17) and food waste (Mak14) as the dominant policy framing or as part of a multi-pronged approach is also related to framing. Poh15 advocates for policy that cuts across issues to maximise effectiveness. The use of knowledge and information emerged, in relation to raising awareness of the climate impact of food (Hun16 and Mak14), skills for reducing meat consumption (Kem20), and nutritional literacy (Urb20). Role of theory is advocated both implicitly and explicitly, with Urb20 recommending Social Judgement Theory, due to identifying a barrier linked to others' beliefs. Nudge Theory is advocated implicitly in three studies (Hoe17, Hun16, and Urb20) by recommending focusing on small behavioural steps to potentially overcome perceived 'difficulty'. This assumes the 'difficulty' barrier corresponds to large or significant behavioural changes, and that smaller, 'achievable' nudges would be more effective, however, this was not shown in any studies. This indicates a discrepancy between the study outcomes and subsequent policy recommendations intended to overcome these barriers, so this was explored further.

Policy recommendations such as education and information strategies clearly link directly to the knowledge barrier in K\&A. Framing and messaging relate directly to value and attitude barriers. Some elements of psychological distance are addressed through framing, knowledge of climate impacts, and some strategies relating to co-benefits (i.e., health). However, there were examples where there appeared to be a broken link between the study findings and the recommendations. Table 2 highlights the barriers that are not addressed through the policy recommendations. Difficulty and habit are most commonly not addressed explicitly in recommendations. Despite habit being categorised as a barrier in five of the studies, it is specifically referenced in the policy recommendations in only one study (Mak14: increase availability to overcome purchasing habits). Difficulty is identified as a barrier in Hoe17, Hun16, Kem20, Mak14, and Poh15. Hoe17, Hun16, and Urb20 advocate for small behavioural shifts, therefore, assumptions are made about small behavioural shifts overcoming the 'difficulty' barrier. Meanwhile, Kem20, Mak14, and Poh15 identify other strategies for overcoming difficulty, such as increasing product availability (Poh15) and targeting food preparation skills to increase vegetarianism (Kem20).

Table 2. Barriers, policy recommendations, and remaining barriers not addressed through policy recommendations, per study.

\begin{tabular}{|c|c|c|}
\hline Study & $\begin{array}{c}\text { Study Outcomes (Barriers) } \\
\text { (Remaining Barriers) }\end{array}$ & Policy Recommendations \\
\hline Cir19 & $\begin{array}{l}\text { Moral and ethical reasons } \\
\text { Meat attachment } \\
\text { Social norms }\end{array}$ & Focus on drivers and address barriers \\
\hline Hoe17 & $\begin{array}{c}\text { Health } \\
\text { Cultural norms } \\
\text { Happy with current behaviour } \\
\text { Attitude to reducing meat consumption vs. increasing } \\
\text { plant-based diet } \\
\text { Low knowledge on environmental impact } \\
\text { Habit } \\
\text { Difficulty }\end{array}$ & $\begin{array}{l}\text { Health messages } \\
\text { Framing-multiple targeted approach } \\
\text { Social norms and emotion } \\
\text { Smaller behavioural shifts }\end{array}$ \\
\hline Hun16 & $\begin{array}{c}\text { 'Threat other' vs. 'threat close' } \\
\text { Understanding of severity and vulnerability of climate } \\
\text { change is significant } \\
\text { Understanding of climate impact } \\
\text { Self-efficacy and response efficacy } \\
\text { Difficulty }\end{array}$ & $\begin{array}{l}\text { Emphasize threat to others } \\
\text { Increase knowledge of climate impact } \\
\text { Start with smaller behaviour changes } \\
\text { Non-climate framing }\end{array}$ \\
\hline
\end{tabular}


Table 2. Cont.

\begin{tabular}{|c|c|c|}
\hline Study & $\begin{array}{c}\text { Study Outcomes (Barriers) } \\
\text { (Remaining Barriers) }\end{array}$ & Policy Recommendations \\
\hline Kem20 & $\begin{array}{c}\text { Knowledge of environmental impact } \\
\text { Difficulty } \\
\text { Lack of trust in supply chains } \\
\text { Enjoyment of meat } \\
\text { Cultural heritage } \\
\text { Childhood associations } \\
\text { Health }\end{array}$ & $\begin{array}{l}\text { Increase information and skills } \\
\text { Target campaigns by life stage/stage of } \\
\text { meat reduction journey }\end{array}$ \\
\hline Mak14 & $\begin{array}{l}\text { Knowledge } \\
\text { Habit } \\
\text { Difficulty }\end{array}$ & $\begin{array}{c}\text { Increase knowledge of climate impacts } \\
\text { Increase availability } \\
\text { Focus on food waste }\end{array}$ \\
\hline Poh15 & $\begin{array}{c}\text { Health } \\
\text { Masculinity, traditionalism and hierarchies } \\
\text { Difficulty } \\
\text { Enjoyment } \\
\text { Existing behaviour }\end{array}$ & $\begin{array}{l}\text { Consider policy across issues } \\
\text { Focus on different value/norm groups } \\
\text { Focus on already 'sympathetic' groups }\end{array}$ \\
\hline Urb20 & $\begin{array}{l}\text { Subjective norms } \\
\text { Others' beliefs } \\
\text { Knowledge of nutrition } \\
\text { Habit } \\
\text { Self-efficacy }\end{array}$ & $\begin{array}{l}\text { Use Social Judgement Theory } \\
\text { Implement small steps } \\
\text { Improve nutritional literacy }\end{array}$ \\
\hline
\end{tabular}

Other examples of the discrepancy between barriers identified and subsequent policy recommendations include how health messages are only advocated strongly in one study (Hoe17), whereas health was identified as a barrier (as part of psychological distance) in Hoe17, Kem20, Poh15, and Urb20. Notable is the lack of policy recommendations that address the emotional elements of behaviour or barriers to behaviour change, i.e., meat attachment or enjoyment (Kem20 and Poh15).

\section{Discussion}

This discussion focuses on overcoming the barriers identified and discusses the application of this research to policy, practice, and research going forward.

\subsection{Kollmuss and Agyeman (KEA)}

Through applying the K\&A model to analysis, habits were found to be the most significant barrier to change. This is supported by the literature which explores habit and broader pro-environmental behaviour change [32]; however, Çoker and van der Linden [15] identified past behaviour, not habits, as a significant factor in predicting behaviour. Habitual behaviour differs from past behaviour, as habit relies on the automatic behavioural system [51] and only changes when external forcing factors change [52]; therefore, this should be considered when designing interventions. Habits are much less frequently researched in the pro-environmental behaviour sphere [53], potentially due to the challenges with longitudinal research and self-reported studies. This suggests that difficulties in researching habit can have knock-on effects for policymakers when designing interventions.

Values and attitudes are commonly identified as barriers, and are found to relate to and affect other barriers (such as emotional attachment to meat and cultural norms). This potentially indicates values and attitudes as moderating variables, which could be an area for future research. Emotional barriers were prominent, with enjoyment being frequently highlighted. Loughnan et al. [54] found negative emotions associated with eating meat were subconsciously discarded, which could indicate that automatic behavioural processes associated with habit are also involved in the emotional elements of meat-eating behaviour. Knowledge is frequently identified as a barrier to change but is heavily tied to emotion and 
values, for example manifesting as disbelief. This highlights the interrelationships between barriers and supports the overall framework of the K\&A model, which portrays a dynamic and multifaceted behaviour change process.

There was widespread overlap between the barriers; and the interrelationships indicate a need to construct interventions which address multiple barriers by considering barriers holistically, as an interrelated whole [47], and reduce the risk of the rebound effect or negative spillover [22].

\subsection{Psychological Distance}

When the remaining barriers were explored through the lens of psychological distance, additional explanatory power is built. There are certain overlaps with some barriers found in $K \& A$, e.g., disbelief in climate (psychological distance) and emotion (K\&A), or threat of climate change (psychological distance) and values (K\&A).

Difficulty and health were the dominant barriers within the concept of psychological distance. The 'difficulty' barrier encompassed the perceived lack of nutritional literacy which would be required to move to a more plant-based diet; contextual factors, such as availability; and the gap between the perception of these barriers and the actual barriers. This broad range of 'difficulties' identified suggests that a one-size-fits-all intervention approach would be ineffective to overcome these multidimensional barriers.

Health was found to be both a barrier and a driver to reducing meat consumption. The distances identified here were often contradictory-beliefs around the " $4 \mathrm{Ns}$ " of meatthat meat is "natural, normal, necessary, and nice" [55] (p. 114), and the health benefits of eating a plant-based diet. Cognitive dissonance such as this has been identified as the 'meat paradox'; where an individual values both animal rights and eating meat [54], which supports a moral disconnect between animal and self [56], further exemplifying a manifestation of psychological distance. This cognitive dissonance was identified as the most significant factor in Stoll-Kleemann and Schmidt's [10] review of factors which influence meat consumption in developed and transition countries. The idea of a disconnect between beliefs around health and the environment that are not evidence based, has been repeatedly identified $[57,58]$.

Social barriers could be targeted to bridge psychological distance or indicate a psychological proximity. Evidence showing that threat 'close' is less effective than threat 'other' could help with framing an intervention, for example framing messaging around impacts on others or social norms. The idea of proximity does not align simply with existing work indicating that distance needs to be bridged for a behavioural shift to occur [39]. This supports McDonald et al.'s [37] findings around 'can climate change get too close?' and calls for a nuanced understanding of bridging distance and facilitating proximity [40].

Categorising most of the barriers (which cannot be explained through K\&A) as uncertainty and social distance, and therefore this provides an opportunity for interventions to overcome them. Social elements of psychological distance could be argued to be discreet and potentially easier to design interventions to be overcome (health behaviour campaigns, communication of threat, etc.). Uncertainty presents nebulous, value-based concepts such as disbelief, trust and familiarity, which could be harder to overcome.

\subsection{Commonalities and Outliers across Barriers}

The exploration of psychological barriers through the two models highlights the inter-relationships between barriers. The outliers-barriers which did not fit into either categorisation-can offer further insight. All three outliers manifest as gaps in an individual's behavioural process. These gaps occurred (1) between behavioural determinants, (2) between barriers themselves, and (3) between the perceptions of barriers and actual barriers. The theme of perception repeatedly emerged, and this is mirrored across general the literature on pro-environmental behaviour change. Gaps were identified between individual's perception of their own knowledge, skills, self-efficacy, and difficulty, which relates to themes of denial [18], and affect barriers in both K\&A and psychological distance. 
It could be argued that values, knowledge, emotion and habit can manifest as direct blocks on behaviour change (as displayed in K\&A). Exploring barriers through the lens of psychological distance suggests that distances (or gaps) can manifest to prevent behaviour change. However, the integration, overlaps, and outliers to these models, show that gaps within the behavioural process can happen in many ways beyond the distances identified within psychological distance. The prominence of the issue of perception indicates a manifestation of psychological distance within the behavioural process itself, in addition to the existing understanding of psychological distance which relates the self to the external [59]. Understanding barriers in a more holistic and integrated sense can enable policymakers and other stakeholders to design interventions that are more effective, by targeting multiple barriers and preventing inadvertent activation of a barrier through mismanagement of another.

\subsection{Overcoming Psychological Barriers}

Lessons can be drawn from the policy recommendations within these studies. Framing and messaging was the most frequently recommended intervention, which aligns with the wider literature [27,60-62]. Tailoring messaging to different value groups could also complement messaging around co-benefits [63]. The difference in attitudes and emotions associated with reducing meat consumption versus increasing plant-based diet/meat substitutes is a clear indication for how framing and messaging need to be built around values, attitudes, social norms (social psychological distance) and emotion [64]. Findings around proximity within social psychological distance, especially in the context of health, supports existing research that highlights health as an effective framing and messaging strategy [42,58]. Findings around co-benefits indicate that if interventions are aligned with related policy areas (i.e., climate and public health policy), opportunities for positive spillover could occur [21,65].

Increasing knowledge around the impacts of climate change and relating that to individual meat consumption could potentially be achieved through informational policies and campaigns. However, the effectiveness of this alone has been widely questioned [18]. Policy focused on overcoming the 'knowledge' barrier only addresses one element of a holistic process (and knowledge was found to be a relatively weak barrier). Instead of applying informational policies to overcome the direct knowledge barrier, focusing on the knowledge manifestation within psychological distance (i.e., difficulty and self-efficacy) could prove more effective through targeting the gaps in the process.

Nudge Theory was frequently implicitly recommended for policy, often in conjunction with another strategy such as informational campaigns. Applying nudge theory to overcome the initial barriers associated with a behaviour being 'too big to change', could be effective in some contexts. However, barriers are interrelated and multifaceted. Nudge Theory taps in to the automatic system of behaviour [51,66], which aligns with psychological distance and behavioural gaps, as the unconscious system drives embedded behaviour which could block change. This merits further research into this mechanism and explorations around why Nudge Theory is so readily advocated. Possible explanations could lie in the existing paradigms in environmental policymaking, i.e., the focus on small, 'achievable' steps advocated by nudge theory, and the reluctance of traditional behavioural economics to advocate for more ambitious interventions.

The themes which emerge in the policy recommendations of the papers reviewed do not focus on the dominant barriers identified within the research, and many barriers are not addressed at all within the policy recommendations. Habit and existing behavioural patterns are formulated from a complex array of determinants and this should be more clearly recognised within policy recommendations, as identifying strategies to overcome one element of a barrier does not consider barriers as a holistic construct.

The disparity between the policy recommendations and the barriers identified could indicate a reliance on research that focuses on encouraging behavioural determinants (as opposed to addressing psychological barriers). It could also indicate a process gap 
within research (basing policy recommendations on traditional/existing policy strategies, as opposed to being led by the findings), or potentially a reluctance to advocate for policy which might be seen as unappealing to policymakers. The complexity of the barriers identified, especially regarding barriers manifesting as gaps, indicates difficulty in creating policy recommendations, or other interventions to overcome barriers.

\subsection{Policy Recommendations}

The following are identified as policy recommendations:

(1) Existing habits are the most significant barrier to change. Interventions should target repeated behaviours.

(2) Messaging and framing of communications should be tailored to individuals/groups underlying values; and these need to be better understood.

(3) The relationship between health and reducing meat consumption for environmental and climate reasons could be utilised to align with individual values.

(4) Incremental interventions that are buildable could be appropriate. The assumptions that underlie these recommendations should be explored.

(5) The potential for co-benefits across other high impact pro-environmental behaviours (i.e., consumption patterns more broadly) and other social issues (i.e., health) is high. Crosscutting policy is required to achieve this, to avoid rebound effects or inadvertent repercussions.

(6) Barriers should be considered holistically to increase effectiveness of interventions and reduce risk of activation of direct or indirect barriers.

The policy recommendations for overcoming psychological barriers should be read in conjunction with the literature on external and contextual barriers, as reductions in meat consumption cannot be achieved by overcoming psychological barriers to change alone.

\subsection{Theoretical Integration}

The integration of the Kollmuss and Agyeman model and psychological distance provides a more comprehensive analytical framework and a critique of the theories. Both captured and categorised barriers identified within the research body, and complemented the other, which increased the explanatory power of the analysis. A more formal development of the K\&A model to include components of psychological distance would be an interesting avenue for future research. There were several barriers which could not be categorised within either the K\&A framework or psychological distance. This indicates that although combining the two frameworks does increase explanatory power, gaps in the behavioural process were difficult to categorise.

Theoretical integration in order to ensure usefulness to policymakers is advocated repeatedly across the literature on pro-environmental behaviour change [67-69]. Enhanced interdisciplinarity across the sustainability-health divide could help to integrate theory more effectively.

\subsection{Limitations}

This study followed a Rapid Evidence Review process, which ensured rigour and transparency in the literature gathering and analysis. Only seven studies were included in the analysis, due to the small number of experimental studies exploring barriers explicitly, as well as the specific focus on psychological barriers (as opposed to contextual barriers). There are several reviews on meat consumption reductions that are highly cited and are of a similar scale, indicating the value and interest in a small-scale review such as this [11,42,70]. Variation in research design makes quantitative claims about significance of variables and barriers difficult, so only general trends can be described. Nevertheless, the thematic structure of the review enables comparisons to be made across study outcomes. Conducting a rapid review has resulted in a potentially narrow conceptualisation of psychological barriers, and this runs the risk of excluding different disciplinary understandings. 


\section{Conclusions}

This Rapid Evidence Review builds on existing work around meat consumption behaviours and interventions targeting reducing meat consumption, as well as the broader environmental psychology literature exploring pro-environmental behaviour determinants and barriers. This work aims to contribute to the growing area of psychological barriers to pro-environmental behaviour, with the hope that the findings are of relevance to researchers and practitioners working on designing interventions. We found that habit was the most significant barrier to reducing meat consumption, and this finding aligns neatly with the Kollmuss and Agyeman (K\&A) model. Values and attitudes were frequently found to be moderators or co-variates of other barriers. Some barriers did not fit into the K\&A model, such as difficulty and self-efficacy, and these remaining study outcomes were categorised within psychological distance. 'Uncertainty' and 'social distance' categories captured the majority of the remaining barriers, with difficulty and health being most frequently identified. However, there were also several barriers which did not fit into either K\&A or psychological distance. These outliers could all be argued to commonly manifest as a gap between determinants and barriers, or between barriers and barriers, or finally, between self-perception of barriers and actual barriers. These findings provide an application and critique of how behavioural theory can be used to analyse research and interventions. The psychological barriers identified should be considered holistically and used to directly inform policies and practices to encourage a reduction in meat consumption and overcome the barriers preventing change. Only through identifying the barriers and understanding the underlying mechanisms can the most effective interventions be created. Further research is needed into conceptualising barriers as gaps across environmental psychology and related disciplines, as the current focus is dominated by behavioural determinants as barriers, instead of barriers in their own right. The question of a disparity between the study outcomes and policy recommendations raises interesting questions. It potentially reflects a lack of critique of the assumptions that researchers work within when considering policy recommendations. A broader, more creative approach to policy recommendations that are not limited to existing dominant policy paradigms would be a welcome approach to future research.

Supplementary Materials: The following are available online at https://www.mdpi.com/article/ 10.3390/su132111582/s1. Figure S1: PRISMA flow diagram. Table S1: Inclusion/exclusion criteria. Table S2: Search strings and returned results.

Author Contributions: Conceptualization, C.G. and K.R.; methodology, C.G.; formal analysis, C.G.; investigation, C.G.; data curation, C.G.; writing-original draft preparation, C.G.; writing-review and editing, K.R.; supervision, K.R. Both authors have read and agreed to the published version of the manuscript.

Funding: This research was funded by the University of Leeds Global Challenge Doctoral Scholarship. The authors would like to acknowledge the support provided through the Rapid Evidence Synthesis Training (REST) programme. REST was organised and delivered through a collaboration between the University of Leeds, The University of Newcastle and the N8 AgriFood Programme and supported by Research England QR-SPF funds from The University of Leeds and University of York.

Institutional Review Board Statement: Not applicable.

Informed Consent Statement: Not applicable.

Data Availability Statement: The data presented in this study are available in the Supplementary Material as well as through the Open Science Framework: 10.17605/OSF.IO/URW64.

Acknowledgments: Many thanks to Mark Reed for his comments on an earlier draft.

Conflicts of Interest: The authors declare no conflict of interest. 


\section{References}

1. Vermeulen, S.J.; Campbell, B.M.; Ingram, J.S.I. Climate Change and Food Systems. Annu. Rev. Environ. Resour. 2012, 37, 195-222. [CrossRef]

2. Steinfeld, H.; Gerber, P.; Wassenaar, T.D.; Castel, V.; Rosales, M.; Rosales, M.; de Haan, C. Livestock's Long Shadow: Environ-Mental Issues and Options; Food and Agriculture Organization: Rome, Italy, 2006; ISBN 92-5-105571-8.

3. Ritchie, H. Meat and Dairy Production. Available online: https:/ /Ourworldindata.Org/Meat-Production (accessed on 7 June 2021).

4. Brunelle, T.; Coat, M.; Viguié, V. Demand-side mitigation options of the agricultural sector: Potential, barriers and ways forward. OCL-Oilseeds Fats Crops Lipids 2017, 24, D104. [CrossRef]

5. Kemper, J.A. Motivations, barriers, and strategies for meat reduction at different family lifecycle stages. Appetite 2020, 150, 104644. [CrossRef] [PubMed]

6. Girod, B.; van Vuuren, D.P.; Hertwich, E.G. Climate policy through changing consumption choices: Options and obstacles for reducing greenhouse gas emissions. Glob. Environ. Chang. 2014, 25, 5-15. [CrossRef]

7. Graça, J.; Godinho, C.A.; Truninger, M. Reducing meat consumption and following plant-based diets: Current evidence and future directions to inform integrated transitions. Trends Food Sci. Technol. 2019, 91, 380-390. [CrossRef]

8. Clonan, A.; Wilson, P.; A Swift, J.; Leibovici, D.G.; Holdsworth, M. Red and processed meat consumption and purchasing behaviours and attitudes: Impacts for human health, animal welfare and environmental sustainability. Public Health Nutr. 2015, 18, 2446-2456. [CrossRef]

9. Lentz, G.; Connelly, S.; Mirosa, M.; Jowett, T. Gauging attitudes and behaviours: Meat consumption and potential reduction. Appetite 2018, 127, 230-241. [CrossRef]

10. Stoll-Kleemann, S.; Schmidt, U.J. Reducing meat consumption in developed and transition countries to counter climate change and biodiversity loss: A review of influence factors. Reg. Environ. Chang. 2017, 17, 1261-1277. [CrossRef]

11. Bianchi, F.; Dorsel, C.; Garnett, E.; Aveyard, P.; Jebb, S.A. Interventions targeting conscious determinants of human behaviour to reduce the demand for meat: A systematic review with qualitative comparative analysis. Int. J. Behav. Nutr. Phys. Act. 2018, 15, 1-25. [CrossRef]

12. Taufik, D.; Verain, M.C.D.; Bouwman, E.P.; Reinders, M.J. Determinants of real-life behavioural interventions to stimulate more plant-based and less animal-based diets: A systematic review. Trends Food Sci. Technol. 2019, 93, 281-303. [CrossRef]

13. Stevens, T. The influence of environmental awareness on inducing lower carbon dietary change in the UK. Meliora Int. J. Stud. Sustain. Res. 2017, 1. [CrossRef]

14. Lorenz, B.A.; Langen, N. Determinants of how individuals choose, eat and waste: Providing common ground to enhance sustainable food consumption out-of-home. Int. J. Consum. Stud. 2017, 42, 35-75. [CrossRef]

15. Çoker, E.N.; Van Der Linden, S. Fleshing out the theory of planned of behavior: Meat consumption as an environmentally significant behavior. Curr. Psychol. 2020, 1-10. [CrossRef]

16. Lacroix, K.; Gifford, R.; Chen, A. Developing and validating the Dragons of Inaction Psychological Barriers (DIPB) scale. J. Environ. Psychol. 2019, 63, 9-18. [CrossRef]

17. Grimmer, M.; Miles, M.P. With the best of intentions: A large sample test of the intention-behaviour gap in pro-environmental consumer behaviour. Int. J. Consum. Stud. 2017, 41, 2-10. [CrossRef]

18. Gifford, R. The dragons of inaction: Psychological barriers that limit climate change mitigation and adaptation. Am. Psychol. 2011, 66, 290-302. [CrossRef]

19. Poortinga, W.; Steg, L.; Vlek, C. Values, Environmental Concern, and Environmental Behavior: A Study into Household Energy Use. Environ. Behav. 2004, 36, 70-93. [CrossRef]

20. Wynes, S.; Nicholas, K.A.; Zhao, J.; Donner, S.D. Measuring what works: Quantifying greenhouse gas emission reductions of behavioural interventions to reduce driving, meat consumption, and household energy use. Environ. Res. Lett. 2018, 13, 113002. [CrossRef]

21. Lanzini, P.; Thøgersen, J. Behavioural spillover in the environmental domain: An intervention study. J. Environ. Psychol. 2014, 40, 381-390. [CrossRef]

22. Capstick, S.; Whitmarsh, L.E.; Nash, N.C.; Haggar, P.; Lord, J. Compensatory and Catalyzing Beliefs: Their Relationship to Pro-environmental Behavior and Behavioral Spillover in Seven Countries. Front. Psychol. 2019, 10, 963. [CrossRef]

23. Grabs, J. The rebound effects of switching to vegetarianism. A microeconomic analysis of Swedish consumption behavior. Ecol. Econ. 2015, 116, 270-279. [CrossRef]

24. Dietz, T.; Gardner, G.T.; Gilligan, J.; Stern, P.C.; Vandenbergh, M.P. Household actions can provide a behavioral wedge to rapidly reduce US carbon emissions. Proc. Natl. Acad. Sci. USA 2009, 106, 18452-18456. [CrossRef] [PubMed]

25. Gifford, R.D.; Chen, A.K.S. Why aren't we taking action? Psychological barriers to climate-positive food choices. Clim. Chang. 2017, 140, 165-178. [CrossRef]

26. McKenzie-Mohr, D. New Ways to Promote Proenvironmental Behavior: Promoting Sustainable Behavior: An Introduction to Community-Based Social Marketing. J. Soc. Issues 2000, 56, 543-554. [CrossRef]

27. Palomo-Vélez, G.; Tybur, J.M.; van Vugt, M. Unsustainable, unhealthy, or disgusting? Comparing different persuasive messages against meat consumption. J. Environ. Psychol. 2018, 58, 63-71. [CrossRef] 
28. Lea, E.J.; Crawford, D.; Worsley, A. Public views of the benefits and barriers to the consumption of a plant-based diet. Eur. J. Clin. Nutr. 2006, 60, 828-837. [CrossRef] [PubMed]

29. Kollmuss, A.; Agyeman, J. Mind the Gap: Why do people act environmentally and what are the barriers to pro-environmental behaviour? Environ. Educ. Res. 2002, 8, 239-260. [CrossRef]

30. Stern, P.C.; Dietz, T.; Abel, T.; Guagnano, G.A.; Kalof, L. A Value-Belief-Norm Theory of Support for Social Movements: The Case of Environmentalism. Hum. Ecol. Rev. 1999, 6, 17.

31. Ajzen, I. The theory of planned behavior. Organ. Behav. Hum. Decis. Process. 1991, 50, 179-211. [CrossRef]

32. Verplanken, B.; Roy, D. Empowering interventions to promote sustainable lifestyles: Testing the habit discontinuity hypothesis in a field experiment. J. Environ. Psychol. 2016, 45, 127-134. [CrossRef]

33. Rogers, R.W. A Protection Motivation Theory of Fear Appeals and Attitude Change1. J. Psychol. 1975, 91, 93-114. [CrossRef]

34. Payne, P. Post-metatheorizing Environmental Behaviours in Environmental Education. Environ. Educ. Res. 2002, 8, 307-314. [CrossRef]

35. Leiserowitz, A.A. American Risk Perceptions: Is Climate Change Dangerous? Risk Anal. 2005, 25, 1433-1442. [CrossRef] [PubMed]

36. Singh, A.S.; Zwickle, A.; Bruskotter, J.T.; Wilson, R. The perceived psychological distance of climate change impacts and its influence on support for adaptation policy. Environ. Sci. Policy 2017, 73, 93-99. [CrossRef]

37. McDonald, R.I.; Chai, H.Y.; Newell, B.R. Personal experience and the 'psychological distance' of climate change: An integrative review. J. Environ. Psychol. 2015, 44, 109-118. [CrossRef]

38. Trope, Y.; Liberman, N. Construal-level theory of psychological distance. Psychol. Rev. 2010, 117, 440-463. [CrossRef]

39. Spence, A.; Poortinga, W.; Pidgeon, N. The Psychological Distance of Climate Change. Risk Anal. 2012, 32, 957-972. [CrossRef]

40. Loy, L.S.; Spence, A. Reducing, and bridging, the psychological distance of climate change. J. Environ. Psychol. 2020, 67, 101388. [CrossRef]

41. Klöckner, C.A. A comprehensive model of the psychology of environmental behaviour-A meta-analysis. Glob. Environ. Chang. 2013, 23, 1028-1038. [CrossRef]

42. Sanchez-Sabate, R.; Badilla-Briones, Y.; Sabate, J. Understanding Attitudes towards Reducing Meat Consumption for Environmental Reasons. A Qualitative Synthesis Review. Sustainability 2019, 11, 6295. [CrossRef]

43. Rees, R.; Oliver, K.; Woodman, J.; Thomas, J. Children's Views about Obesity, Body Size, Shape and Weight: A Systematic Review; EPPI-Centre, Social Science Research Unit, Institute of Education, University of London: London, UK, $2009 ;$ p. 148.

44. Hoek, A.C.; Pearson, D.; James, S.W.; Lawrence, M.A.; Friel, S. Shrinking the food-print: A qualitative study into consumer perceptions, experiences and attitudes towards healthy and environmentally friendly food behaviours. Appetite 2017, 108, 117-131. [CrossRef]

45. Hunter, E.; Röös, E. Fear of climate change consequences and predictors of intentions to alter meat consumption. Food Policy 2016, 62, 151-160. [CrossRef]

46. Mäkiniemi, J.-P.; Vainio, A. Barriers to climate-friendly food choices among young adults in Finland. Appetite 2014, 74, 12-19. [CrossRef]

47. Pohjolainen, P.; Vinnari, M.; Jokinen, P. Consumers' perceived barriers to following a plant-based diet. Br. Food J. 2015, 117, 1150-1167. [CrossRef]

48. Urbanovich, T.; Bevan, J.L. Promoting Environmental Behaviors: Applying the Health Belief Model to Diet Change. Environ. Commun. 2020, 14, 657-671. [CrossRef]

49. Circus, V.E.; Robison, R. Exploring perceptions of sustainable proteins and meat attachment. Br. Food J. 2019, 121, 533-545. [CrossRef]

50. Gifford, R. A General Model of Social Dilemmas. Int. J. Ecol. Econ. Stat. 2006, 4, 1-17.

51. Tyers, R. Nudging the jetset to offset: Voluntary carbon offsetting and the limits to nudging. J. Sustain. Tour. 2018, 26, 1668-1686. [CrossRef]

52. Steg, L.; Vlek, C. Encouraging pro-environmental behaviour: An integrative review and research agenda. J. Environ. Psychol. 2009, 29, 309-317. [CrossRef]

53. Russell, S.V.; Young, C.W.; Unsworth, K.L.; Robinson, C. Bringing habits and emotions into food waste behaviour. Resour. Conserv. Recycl. 2017, 125, 107-114. [CrossRef]

54. Loughnan, S.; Bastian, B.; Haslam, N. The Psychology of Eating Animals. Curr. Dir. Psychol. Sci. 2014, 23, 104-108. [CrossRef]

55. Piazza, J.; Ruby, M.B.; Loughnan, S.; Luong, M.; Kulik, J.; Watkins, H.M.; Seigerman, M. Rationalizing meat consumption. The 4Ns. Appetite 2015, 91, 114-128. [CrossRef]

56. Graça, J.; Calheiros, M.M.; Oliveira, A. Moral Disengagement in Harmful but Cherished Food Practices? An Exploration into the Case of Meat. J. Agric. Environ. Ethic. 2014, 27, 749-765. [CrossRef]

57. Leire, C.; Thidell, Å. Product-related environmental information to guide consumer purchases-A review and analysis of research on perceptions, understanding and use among Nordic consumers. J. Clean. Prod. 2005, 13, 1061-1070. [CrossRef]

58. Stubbs, R.J.; Scott, S.E.; Duarte, C. Responding to food, environment and health challenges by changing meat consumption behaviours in consumers. Nutr. Bull. 2018, 43, 125-134. [CrossRef]

59. Van Boven, L.; Kane, J.; McGraw, A.P.; Dale, J. Feeling Close: Emotional Intensity Reduces Perceived Psychological Distance. J. Personal. Social Psychol. 2010, 98, 872-885. [CrossRef] 
60. Graham, T.; Abrahamse, W. Communicating the climate impacts of meat consumption: The effect of values and message framing. Glob. Environ. Chang. 2017, 44, 98-108. [CrossRef]

61. Vainio, A.; Irz, X.; Hartikainen, H. How effective are messages and their characteristics in changing behavioural intentions to substitute plant-based foods for red meat? The mediating role of prior beliefs. Appetite 2018, 125, 217-224. [CrossRef]

62. Stea, S.; Pickering, G.J. Optimizing Messaging to Reduce Red Meat Consumption. Environ. Commun. 2018, 13, 633-648. [CrossRef]

63. Sanchez-Sabate, R.; Sabaté, J. Consumer Attitudes Towards Environmental Concerns of Meat Consumption: A Systematic Review. Int. J. Environ. Res. Public Health 2019, 16, 1220. [CrossRef]

64. Macdiarmid, J.I. Is a healthy diet an environmentally sustainable diet? Proc. Nutr. Soc. 2013, 72, 13-20. [CrossRef] [PubMed]

65. Truelove, H.B.; Carrico, A.R.; Weber, E.U.; Raimi, K.T.; Vandenbergh, M.P. Positive and negative spillover of pro-environmental behavior: An integrative review and theoretical framework. Glob. Environ. Chang. 2014, 29, 127-138. [CrossRef]

66. Oliver, A. From Nudging to Budging: Using Behavioural Economics to Inform Public Sector Policy. J. Soc. Policy 2013, 42, 685-700. [CrossRef]

67. Kennedy, L.; Bishop, I.D. Land Use Decision Making in a Virtual Environment. In Landscape Analysis and Visualisation: Spatial Models for Natural Resource Management and Planning; Pettit, C., Cartwright, W., Bishop, I., Lowell, K., Pullar, D., Duncan, D., Eds.; Springer: Heidelberg, Germany, 2008; pp. 591-608. ISBN 978-3-540-69168-6.

68. Klöckner, C.A.; Blöbaum, A. A comprehensive action determination model: Toward a broader understanding of ecological behaviour using the example of travel mode choice. J. Environ. Psychol. 2010, 30, 574-586. [CrossRef]

69. Zur, I.; Klöckner, C.A. Individual motivations for limiting meat consumption. Br. Food J. 2014, 116, 629-642. [CrossRef]

70. Bianchi, F.; Garnett, E.; Dorsel, C.; Aveyard, P.; Jebb, S.A. Restructuring physical micro-environments to reduce the demand for meat: A systematic review and qualitative comparative analysis. Lancet Planet. Health 2018, 2, e384-e397. [CrossRef] 